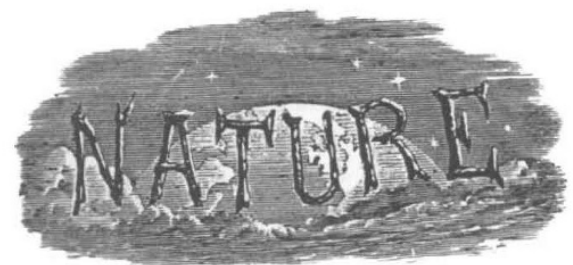

SATURDAY, JULY 9, I932

\title{
CONTENTS
}

Professional Codes and Business Practice

PAGE Vitamins

The Nature of Physical Theory. By Dr. Norman R. Campbell

Science and Poetry. By F. S. M.

Sugar Cane Entomology. By Dr. A. D. Imms, F.R.S. Short Reviews

Prof. Planck and the Principle of Causality in Physics. By Dr. Allan Ferguson

Jérôme de Lalande, I732-1807.

New Buildings for the University of London. By T. L1. H.

News and Views

Letters to the Editor:

New Evidence for the Neutron.--Irène Curie and F. Joliot

Concentration of Slow Neutrons in the Atmosphere.-P. B. Moon .

Currents produced by the Gills of Mayfly Nymphs.

Discontinuous Distribution in Bees.-Prof.

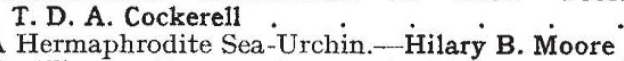

A Hermaphrodite Sea-Urchin.-Hilary B. Moore Electrons.-Dr. Henry de Laszlo and V. E. Cosslett

Influence of Light on Paramagnetic Susceptibility. -Dr. C. J. Gorter

Infra-Red Bands in the Aurora.-Prof. Joseph Kaplan Reactions in Enzymatic Catalysis.-Prof. J. B. S. Haldane, F.R.S.

Occurrence of Bathynella in England.- $\dot{A}$. $\dot{G}$. Lowndes; Dr. W. T. Calman, F.R.S.

River Gauging and Flood Prevention.-Capt. W. N. McClean

Scientific Method.-William P. D. Wightman

Research Items

Astronomical Topics .

Robert Brown and the Cell Theory. By A. B. R

The Value of 'Protective' Adaptations of Animals. By B.P. U.

Aluminium in Foodstuffs .

Carnegie Grants for Libraries and Museums

University and Educational Intelligence

Calendar of Geographical Exploration

Societies and Academies

Forthcoming Events

Official Publications Received

Editorial and Publishing Offices:

MACMILLAN \& CO., LTD.

ST. MARTIN'S STREET, LONDON, W.C.2

Editorial communications should be addressed to the Editor

Advertisements and business letters to the Publishers

Telephone Number: WHITEHALL 8831

Telegraphic Address: PHUSIS, LESQUARE, LONDON

No. 3271 , Voc. 130]

\section{Professional Codes and Business Practice}

NE of the most interesting features in the recently published report of the Medical Research Council for 1930-31 is the evidence it affords of growing relations between the medical profession and manufacturing firms. The disinclination of such professions as law and medicine to have connexion with trade is an inherited prejudice which, however natural or healthy in its origin, in modern society can be greatly to the public disadvantage. As the report points out, the greater reluctance of medical men in Great Britain as com. pared with their continental colleagues to undertake clinical trials of new synthetic substances of therapeutic importance in co-operation with manufacturers, and to publish the results over their own names, frequently militates against the clinical application of scientific research carried out at the universities. New substances first produced in Great Britain sometimes come into general recognition and use by way of clinical reports published in German and other foreign journals.

The problem of securing trustworthy clinical trials of new substances produced by manufacturing firms has recently been discussed by the Medical Research Council with representatives of the Association of British Chemical Manufacturers, and a Therapeutic Trials Committee has been organised under the supervision and authority of which trials of new products may be arranged. This Committee is in close touch with the Chemotherapy Committee, which may be responsible for the experimental work desirable or necessary before the drugs or preparations are used in man, and, in consultation with the Association of British Chemical Manufacturers, agreed conditions have been accepted under which the new substances may be submitted to the Therapeutic Trials Committee for clinical study.

These developments, while affording a welcome indication of the breakdown of earlier prejudices against participation in industry, are only a new phase of relations between the Medical Research Council and chemical industry which have existed for some time. The function of the Council to assist in rendering the results of scientific discovery available for the public and the medical profession frequently involves establishing close co-operation between the original scientific workers and those whose work is concerned with the developments necessary for manufacture and application of the discovery. Only by such co-operation is it often possible to minimise the delay in the elaboration of the necessary technique for economic and successful 
production on a large scale. It is thus inevitable that some relations with chemical industry should exist, and the closer the co-operation the easier it is to negotiate the difficult path between the laboratory discovery and successful manufacture, and the more rapidly will the manufactured product become available for general clinical use.

This problem of development is, however, by no means peculiar to pharmaceutical preparations. It is encountered in many other fields of industry, where new and improved products are continuously being developed as a result of research. The adage that the good is enemy of the best finds perennial expression in, for example, engineering, where the manufacturer of a new and greatly improved alloy is often faced with the problem of convincing a prospective user that it is worth while paying ten per cent more for an article which is really a hundred per cent better than the original. It is undeniable that the successful application of research is largely dependent upon the user's appreciation of the value of the products which it puts at his disposal. Unless the user-who is not necessarily the ultimate public, but may be a professional man, such as a physician, or a manufacturing firm purchasing, for example, alloys for constructional purposes-is ready to adopt new products, the manufacturer finds little encouragement for his expenditure on the development of new and improved articles. The difficulty is increased because, under the present conditions of trade and industry, the mechanism of buying and selling departments is largely in the hands of those who are not trained technicians, and are unable to assess independently the merits of the new products, or to distinguish exaggerated or unreliable claims made in advertising literature.

Serious efforts are, of course, being made to overcome this difficulty in fields other than that of medicine. The Institute of Metals, for example, has endeavoured to bring into personal contact the technical as well as the business men concerned with the manufacture of materials and their application in engineering and elsewhere. Much of the propaganda literature now issued by industrial firms is highly informative and frequently contains scientific data not published elsewhere and of real value to users of the products described. Such publications are now being treated much more seriously, and deserve no longer to be confined to the offices of the buying department, but to be indexed and circulated to the technical staff in the same way as the recognised scientific journals in which much of the information may be afterwards published.
In spite of these efforts, absence of technical knowledge in the buying department may often lead to a mistaken insistence on a cheaper material when the new and possibly more expensive product would really prove far more satisfactory or economical, and at the best the wheels of progress are clogged and efforts to improve products are hampered.

Thus the experience of such diverse industries as the metal and engineering industries and the fine chemical industry indicates that much more is being demanded of scientific workers in every aspect of industry, and that progress demands the rapid disintegration of those prejudices which formerly kept professional men and industry apart. The scientific outlook and a scientific or technical training are becoming as important, if not as indispensable, in the buying and selling organisations of industry as in the control of technical operations or in research. Equally it appears that the scientific worker might make an important contribution even in the publicity or advertising side of industrial organisations, at which in the past he has been prone to look askance. It is only as he contributes both his scientific knowledge and his professional integrity and traditions to the development of advertising literature of real scientific merit that some of the obstacles to the development of new products can be most easily overcome. The development of such methods in advertising is a logical outcome of the rationalisation of industry, but its achievement requires the co-operation of scientific workers as professional men. The report of the Medical Research Council already makes it plain that such professional co-operation is imperative in the public interest if new remedies are to be tested and developed adequately, and a change in the attitude of the medical profession to advertising seems inevitable.

Fundamentally these changes or tendencies are but an indication of the impossibility of dealing with industry or society in watertight compartments, or of restricting the influence of scientific thought once scientific methods have been applied to any extent. Inevitably a scientific outlook is required in every sphere of life, and while this will only be attained when science finds its rightful place in our educational system, much depends on the contribution of the scientific worker himself. It is only as he is brought into closer and more open contact with the general public that society can understand the true meaning of scientific methods and their contribution to the common weal.

The task which thus devolves on scientific

$$
\text { No. } 3271 \text {, VoL. 130] }
$$


workers is by no means simple. While safeguarding their professional codes and standards of qualification, they are called upon to participate in the general life of the community, divesting themselves of that air of mystery which hinders the proper appreciation of their work and is often regarded as a cloak for humbug and inefficiency. We cannot expect that science and its methods will exercise the influence that is so essential to-day, in all aspects of social and economic life, unless in their own professional conduct and organisations scientific men are dominated by scientific and rational principles. Habits tending to secrecy, with the encouragement which they inevitably give to quackery, must definitely be discarded; and the indications that the medical profession is more disposed to co-operate with other classes of scientific workers and to abandon older prejudices are the more welcome because conservatism and the species of mental inbreeding which it engenders are among the greatest dangers to the efficiency of professional workers, whether in science or in other fields of human endeavour.

\section{Vitamins}

The Vitamins. By Dr. Ethel Browning. (Monographs of the Pickett-Thomson Research Laboratory, Vol. 1.) Published for the Pickett-Thomson Research Laboratory. Pp. xxxii $+575+7$ plates. (London: Baillière, Tindall and Cox ; Baltimore, Md. : The Williams and Wilkins Co., 1931.) 42s. net.

CONFRONTED with a volume such as that $\cup$ recently written by Dr. Ethel Browning, a reader becomes acutely aware of the interest which the discovery of vitamins has aroused throughout the scientific world and the enormous amount of work this has elicited in the brief period of one decade. It is probably true to say that no other fundamental discovery in biological science has led to such concentrated research in so short a time.

Various kinds of books on the subject of vitamins can be imagined, but two types suggest themselves at once: one to tell the general public the entrancing story of their discovery, history, and practical importance in health; the second to set out for the teacher and laboratory worker the detailed facts of their action and to guide him in tracking down the original source of knowledge on individual points. The writer of either of these books should be possessed of the wisdom of Solomon, but in the second case he must also have a more extensive knowledge, not only of physiology, pathology, and medicine, but also of physics and chemistry, as No. 3271, VoL. 130] well as a personal experience of laboratory and clinical feeding tests.

Popular books on vitamins have been published from time to time, but the majority of the writers leave the average reader with a feeling that vitamins are substances of great importance only for polar explorers and those whose diet consists of polished rice. The fact is, of course, that the discovery of these substances and their actions is leading to one of the greatest silent revolutions Great Britain has ever experienced, a revolution in health and physical welfare, which will compare in magnitude with that following the discovery of the part played by micro-organisms in disease. It is becoming more generally recognised that in some respects the nutritional condition of our population is appalling, and that an infinite amount of physical defect, pain, and ill-health results from improper feeding, especially in early life. Knowledge of the nutritional factors responsible for such widespread defects as rickets, decayed teeth and pyorrhœea, and their sequelæ is being firmly established. Instead of an ill-grown, bandy-legged, anæmic population with septic and edentulous mouths, we already know how to substitute a taller, heavier, straightlimbed race with well-grown jaws and strong, healthy teeth. A popular book on vitamins should tell the world these facts and how they can be procured. Ultimately even the politician might be moved to do something in the matter and direct his attention to the prevention rather than the cure of disease.

The second type of book, namely, that dealing in a comprehensive way with all the scientific facts at present known about vitamins, had obviously to be written if progress was not to be impeded by needless repetition, by saturation of the research mind with a mass of unco-ordinated facts, and by endless waste of individual time in exploring the literature. So early as 1919 the Medical Research Council prepared a monograph of this kind; a second edition appeared in 1924, while the third is now in the press. This book has been written by a group of experts and practical workers, for it was thought only in this way could a satisfactory standard be reached. Now we find Dr. Ethel Browning tackling the job single-handed. The least the present reviewer can do is to bow his head and express his admiration of her pluck and energy in making such an attempt. This emotion is not lessened when he sees that the book is of quarto size, contains 432 pages of text, 90 pages of references to literature, about 50 pages of index of authors and subjects, and 7 excellent plates showing 